\title{
Una revolución neoliberal: la política educacional en Chile desde la dictadura militar
}

Natalia Slachevsky Aguilera ${ }^{\mathrm{I}}$

\section{Resumen}

El artículo propone una lectura analítica del sistema educacional chileno a partir de la dictadura cívico-militar, encabezada por Augusto Pinochet (1973-1990), en la que se transforma el modelo social, económico y político del país, imponiendo un Estado neoliberal incluso antes de que este modelo se vislumbrara como el horizonte en el resto de la región. Se recorre el proceso de transformación del sistema de educación chileno, los cambios en la morfología del sistema escolar y sus consecuencias, así como la consolidación de esta matriz durante los gobiernos democráticos de la coalición de centro izquierda, la Concertación (1990-2010). Si bien el desarrollo de este proyecto educacional se inicia con fuertes tensiones ideológicas entre el catolicismo y el liberalismo, estos logran converger en el principio de libertad de enseñanza. Bajo esta premisa, se articulan numerosas reformas que dan forma a un sistema educacional neoliberal. En consecuencia, se dará cuenta de la configuración de un nuevo orden educativo, hoy arraigado en la sociedad chilena, en el que la educación se establece como un bien individual bajo la égida de la competencia generalizada, el objetivo de la eficiencia y la cultura de la evaluación. Este artículo surge en el marco del desarrollo de mi tesis doctoral y se basa principalmente en el análisis de literatura académica y textos oficiales.

\section{Palabras claves}

Educación - Neoliberalismo - Evaluación - Competencia - Chile.

I- Université Paris Descartes, Paris, Francia.

Contacto: nslachevsky@gmail.com 


\title{
A neoliberal revolution: the educational policy in Chile since the military dictatorship
}

Natalia Slachevsky Aguilera'

\begin{abstract}
This article presents an analytical reading of the Chilean education system since the civic military dictatorship, led by Augusto Pinochet (1973-1990), in which the social, economic and political systems of the country are transformed by imposing a neoliberal State even before such model was glimpsed as the horizon in the rest of the region. It reviews the transformation process of the Chilean education system, the changes in the morphology of the school system and their consequences, as well as the consolidation of this matrix during the democratic governments of the center-left coalition, "La Concertación" (1990-2010). Even though the development of this education project starts with strong ideological tensions between Catholicism and liberalism, they manage to converge in the principle of freedom of teaching. Under this premise, several reforms are implemented in order to shape a neoliberal education system. Consequently, the configuration of a new educational order will be discussed, ingrained in the Chilean society nowadays, in which education is considered an individual good under the aegis of general competition, efficiency objectives and the evaluation culture. This article emerges within the framework of the development of my $P h D$ and it is mainly based on the analysis of academic literature and official documents.
\end{abstract}

\section{Keywords}

Education - Neoliberalism - Evaluation - Competition - Chile.

I- Université Paris Descartes, Paris, França Contact : nslachevsky@gmail.com 


\section{Introducción}

Los sistemas educativos están en crisis, y sus viejos estandartes, la idea de la escuela republicana o aquella de la emancipación a través del conocimiento, parecen obsoletos. En este contexto, la ideología neoliberal ha ido monopolizando progresivamente, por doquier, los discursos y las dinámicas de las reformas educativas a adoptar (LAVAL, 2004).

En América Latina esta tendencia se empezó a manifestar a fines de los años 1980 con la aplicación de un conjunto de reformas estructurales con fuerte orientación neoliberal, en línea con las recomendaciones del llamado Consenso de Washington. Organismos internacionales como el Fondo Monetario Internacional, el Banco Mundial y las Naciones Unidas tuvieron un rol preponderante, al sugerir y recomendar modernizaciones a los viejos sistemas educativos regionales, catalogados de ineficientes. En base a estas orientaciones, distintos países de la región comenzaron a desarrollar políticas educacionales que favorecieron la privatización del sistema educativo, incentivando la descentralización y la disminución de la inversión estatal, para incrementar la competitividad de las escuelas. Así los distintos países fueron implementando estas políticas, cada uno con sus especificidades pero bajo la misma matriz.

En Chile, la implementación del neoliberalismo comenzó más de una década antes que el resto de América Latina. En efecto, es bajo el régimen de Augusto Pinochet que se pone en práctica por primera vez en la región -y en el mundo- lo que más tarde se denominará el modelo neoliberal (HARVEY, 2007). Y, en lo que nos interesa, es en Chile donde, tal vez, se da la expresión más pura del modelo educacional neoliberal. Progresivamente, este ha ido preconizando el culto a la eficiencia, generalizando la competencia en todos los niveles, instaurando la cultura de la evaluación y entronizando el mérito como modelo de justicia social.
Este artículo propone un estudio crítico del neoliberalismo en la educación a través del caso chileno, apoyándonos, sobre todo, en los cambios que produjo la implementación de este modelo en la morfología del sistema educacional y en sus principales consecuencias.

\section{Memorias del sistema escolar chileno}

Los origenes de la institución escolar en Chile tienen raíces republicanas. Desde principios del siglo XIX, cuando el país se independizaba de la corona española, se abogó por un Estado responsable del desarrollo de un sistema educativo nacional, cuestión esencial para la formación de ciudadanos. Cabe destacar, que la formación de ciudadanía no pretendía favorecer a toda la población, sino que se reservaba a una élite, las clases dirigentes, aquellas que tenían la misión de gobernar y conducir al país hacia el desarrollo. En ese contexto, no es de extrañar que desde el inicio de la República la atención educacional se vio como una manera de conservar el orden social oligárquico. En pocas palabras, se trataba de un modelo oligárquico con inspiraciones republicanas, pero con escasa preocupación democrática.

Desde esta época, el Estado en Chile desarrolla un sistema educacional en dos grandes niveles, cada uno de ellos en función de los intereses y de las necesidades educativas de las élites dominantes. Desde 1920, con la Ley de educación primaria obligatoria se consolidan las escuelas primarias públicas para las clases trabajadoras, mientras para la oligarquía estaban las clases preparatorias de educación secundaria, y un sistema de educación superior ampliamente reservada para este sector social. Desde entonces hubo diversas políticas para ampliar el sistema educacional, sin embargo esta estructura en su matriz quedó prácticamente incólume hasta la reforma de los años 1960 (RUIZ SCHNEIDER, 2010).

Los principios republicanos que dan cuerpo al modelo educativo chileno, 
acompañan su desarrollo a lo largo de casi dos siglos, en el transcurso de los cuales diversas ideas educacionales van orientando o complementando la política del Estado. Nos parece relevante subrayar cómo el paradigma económico comienza a tomar fuerza en el campo educativo ya a principios del siglo XX con las concepciones nacionalistas de la educación, que abogan por priorizar la formación de trabajadores-productores por sobre la de ciudadanos. Esta importancia paradigmática de las consideraciones propiamente económicas en la educación se harán incluso más explícitas en los años 1960 con el modelo desarrollista, y sobre todo con las transformaciones que en la década de 1980 imponen las teorías de mercado neoliberal (RUIZ SCHNEIDER, 2010).

Se podría decir que la reforma de los años 1960 da cuenta de un mayor esfuerzo por democratizar la educación, y permitir así una mayor cohesión social. En este afán se incrementa la instrucción básica obligatoria a una escolarización de ocho años, y se permite una mayor flexibilidad de las trayectorias científico-humanistas y técnico-profesional en la educación media, sin predeterminarles a priori a los alumnos la salida al mercado laboral o a la universidad, permitiendo en ese sentido una elección más tardía. Se amplía además el acceso a la educación superior, en la que se abren espacios de mayor participación y compromiso con los desafíos de crecimiento del país. Este ímpetu más democrático prospera, empero sin poner en cuestión las consideraciones de orden económico, fundamentales para el modelo desarrollista. En éste, la educación tiene un rol sustancial en la formación de capital humano capacitado técnicamente para poder desarrollarse en la industria. No debemos olvidar que en esa época son los organismos internacionales, que después de promover la industrialización de la región como vía para el desarrollo en la Alianza para el Progreso, quienes ponen especial énfasis en el desarrollo de los sistemas educativos para hacer frente a los nuevos desafíos.
En resumen, a lo largo del siglo XX, a partir de una matriz republicana elitista que se mantuvo vigente a pesar de un conjunto de esfuerzos democratizadores, se desarrolla enormemente el sistema educacional chileno. Esto permite que a principios de los años 1970, Chile goce de un sistema educacional en el que un 78\% de la matrícula es en establecimientos públicos y un 22\% en colegios particulares (COX; JARA, 1989), de los cuales muchos se beneficiaban de las subvenciones estatales, por lo tanto eran gratuitos, aplicaban los planes y programas oficiales y se sometían a la supervigilancia del sector público (PIIE, 1984). Existe por lo demás una estructura de educación superior compuesta de ocho universidades que imparten carreras técnicas y profesionales, dónde el sistema público concentra en 1973 un 67\% del alumnado (BRUNNER, 1986).

El sistema prevé además, en la época, de un dispositivo de ayuda escolar, la JUNAEB (Junta Nacional de Auxilio escolar y Becas), que asiste a estudiantes en situación de pobreza para que puedan acceder al sistema educativo y perdurar en él, principalmente a través de programas de alimentación. Desde principio de los años 1970 cuenta también con un estamento autónomo para atender la educación pre-escolar, la JUNJI (Junta Nacional de Jardines Infantiles). El conjunto del sistema escolar, que tiene una estructura bastante compleja, está piloteado por el ministerio de educación pública.

En 1973 la cobertura escolar según tramo etario es de $6,4 \%$ en pre-básica, $106,4 \%{ }^{1}$ en educación básica, 42,9\% en educación media y 16,8\% en educación superior (COX; JARA, 1989). La tasa nacional de analfabetismo era de 11\% en 1970 (COX, 2005). En 1973, el gasto fiscal en educación es de 4,3\% del PIB, lo que corresponde al 10\% del gasto fiscal total, que se descompone en 43\% en educación pre-escolar y básica, 16\% a la educación secundaria, y 41\%

1- No hay explicación en el texto de Cox y Jara (1989) sobre este dato, sin embargo otros textos señalan que la cifra se debe a la incidencia de la matrícula en el sistema primario de alumnos mayores que no corresponden al tramo etario señalado. 
a educación superior (COX; JARA, 1989). Es importante poner atención en la composición del gasto, a pesar de la expansión del modelo desarrollista, y de la corta experiencia del socialismo, casi la mitad del gasto iba a la educación superior, a la que solo accedía un $17 \%$ de la población de su respectivo tramo etario, sin duda, la más privilegiada. La inversión polarizada en la enseñanza básica y en la superior, en desmedro de la educación media, dan cuenta en el fondo que nunca se superó completamente la estructura educativa que favorecía a las élites dominantes.

\section{Golpe en el aula²}

En septiembre 1973 los militares -con la venia de un importante sector de civilesderrocan el gobierno de la Unidad Popular con un golpe de Estado espectacular: el bombardeo de la casa de gobierno, el presidente Allende que lucha hasta el final y muere en ella. Desde entonces, se impone un régimen militar autoritario y sangriento conducido por la junta de gobierno en la que participan los 3 comandantes jefes de la fuerzas armadas y el general director de carabineros, asumiendo rápidamente Augusto Pinochet, Comandante en Jefe del ejército, el mando de la cuadrilla. Bajo la doctrina de seguridad del Estado se impone un régimen de represión y persecución que se prolongará por 17 años, en los que se atenta sistemáticamente contra los derechos humanos, característica compartida por el resto de las dictaduras que, en el Cono Sur, se instauraban en esa época. La particularidad de este caso, son las transformaciones estructurales que de a poco se empiezan a percibir, y que a la larga dan paso a la refundación del Estado de Chile y de sus instituciones, incluida en ellas, el sistema educacional. Desde 1975 se empieza a poner en marcha un nuevo modelo social que impone la competencia y el mercado por doquier, es el comienzo de la construcción del

\section{2- Título utilizado por Mönckeberg (2006).}

Estado neoliberal encabezado por gremialistas e intelectuales neoliberales. Sin embargo, no será sino hasta fines de la década de los 1970, en que el gobierno establecerá una agenda para las transformaciones educacionales, con directrices claramente neoliberales, que anuncian una reforma radical del sistema educacional.

En un primer periodo, más allá de las políticas represivas que se aplican en toda la estructura del sistema educacional para eliminar las ideas marxistas, o incluso las posibles críticas que pudiesen surgir al régimen militar, no hay una orientación clara de qué hacer en educación (PIIE, 1984). Es importante recalcarlo, los militares que hicieron el golpe de Estado, educados bajo la doctrina de seguridad nacional, tenían por principal objetivo combatir el comunismo. Cargaban con valores castrenses de orden e identificación con el alma nacional entre otros, pero no eran portadores explícitamente de un proyecto político para el país. Existía receptividad tanto al discurso neoliberal, como a un discurso estatistadesarrollista, e incluso al corporativismo de Estado, lo que dio lugar, al menos en un primer momento, a orientaciones políticas que muchas veces podían ser incoherentes e incluso contradictorias (VALDIVIA, 2001).

En relación a los valores que debe inculcar la educación, se resalta así, desde el inicio, y de manera discordante, la importancia de "valores morales y espirituales propios de la tradición chilena y cristiana" (CHILE, 1974, p. 12), en paralelo a la importancia acordada al mérito y al esfuerzo personal como valores del gobierno nacionalista (CHILE, 1974), que incitan la competencia como un instrumento de desarrollo colectivo. Se afirma también que la educación debe perfeccionar integralmente a las personas, con valores morales, patrióticos y científicos (PIIE, 1984). Pero de a poco este discurso, declaradamente moralista, empieza a deslavarse frente a preocupaciones que tienden centrarse en el rendimiento académico de los alumnos.

Los documentos en materia educacional de los primeros años de la dictadura dan 
cuenta, fehacientemente, de la inexistencia de un proyecto único en la materia. Se podría decir que hubo más bien una pugna ideológica entre orientaciones católico-conservadoras y orientaciones neoliberales, ambas con fuerte acerbo nacionalista, pero que no permitían tener una visión homogénea de la institución educacional a la cual aspirar.

El ala católico-conservadora aboga por continuar un sistema nacional de educación coordinado y planificado por el Estado, éste debía seguir siendo el responsable de la educación (PIIE, 1984). Esta posición da cuenta de una cierta inercia de la concepción educativa desarrollista, que caracterizó históricamente, como lo hemos señalado, el sistema educacional chileno (RUIZ SCHNEIDER, 2010).

Por otro lado, se percibe la consolidación de una nueva derecha, neoliberal, que comienza a poner en discurso la necesidad de un Estado subsidiario que viniera a reemplazar el antiguo Estado Docente. Se observan fuertes críticas al estatismo exagerado, culpable de concebir una sociedad "gris, uniforme, sometida y sin horizontes" (CHILE, 1974, p. 4) y de imposibilitar "de hecho la vigencia de una verdadera libertad de enseñanza” (CHILE, 1978 apud PIIE, 1984, p. 87) ${ }^{3}$. Se atisban además propuestas de privatización del sistema escolar, buscando por un lado incrementar su eficiencia y disminuir el gasto social.

Ambos proyectos, el católico-conservador como el neoliberal, son reacciones al gobierno de la Unidad Popular, con concepciones sin embargo muy distintas en relación al rol que debe cumplir el Estado en materia de educación.

\section{La senda de la libertad}

Si bien históricamente es el Estado de Chile quien desarrolla el sistema educativo, éste nunca monopolizó la función docente, y la participación de otras instituciones como la iglesia o la masonería por ejemplo, fue fundamental para ampliar esta labor. La

3- Declaración pública del Ministerio de Educación. El Mercurio, Santiago, 5 de marzo de 1978. libertad de enseñanza se reconoce de facto desde principios del siglo XX -la Constitución de 1933 la garantiza. A pesar de esta herencia, los documentos educativos del régimen militar enfatizan fuertemente en la necesidad de garantizar este derecho, como si se le hubiese vulnerado bajo el gobierno de Salvador Allende (1970-1973).

La libertad de enseñanza es un principio que se compone de 3 dimensiones: la libertad académica o de pensamiento; la libertad de emprender y hacer funcionar un proyecto educativo; y la libertad de las familias de elegir un establecimiento escolar en el que educar a sus hijos. Bajo el régimen de Pinochet, sólo se resguardaran dos de estas tres libertades: la libertad de crear un proyecto educativo y la libertad de elección de los padres de familia como consumidores de educación. La tercera arista de la libertad de enseñanza, la libertad del saber va a ser, por el contrario, puesta bajo vigilancia, limitada y relativizada por la doctrina de seguridad nacional.

Será alrededor de estas dos dimensiones de la libertad de enseñanza como se va a producir, progresivamente, la confluencia entre estas dos visiones -católica-conservadora y neoliberal. En efecto, por una parte, la filosofía católica va a defender acérrimamente este principio desde el siglo XIX, al subrayar el derecho sagrado de las familias a escoger los centros docentes en los cuales educar a sus hijos. Por otra parte, para los neoliberales, la libertad de elección es fundamental para asegurar la autonomía de los individuos, como su responsabilidad. Es "un principio de eficiencia económica, así como un antídoto a toda deriva coercitiva del Estado" (DARDOT; LAVAL, 2010, p. 193). Desde esta perspectiva la libertad de enseñanza, primordial para la doctrina neoliberal, es entendida en tanto derecho soberano del consumidor de elegir el proveedor educativo por una parte, así como la libertad de emprender proyectos educativos por otra, y aumentar la oferta educativa adaptándola de mejor manera a los deseos de las familias. 
En la esfera educacional, la libertad de enseñanza es pues el punto de convergencia entre católicos conservadores y neoliberales, derecho básico para ambas corrientes. Es el Estado subsidiario, figura defendida a su vez por la corriente católica, y puesta en valor por los neoliberales, quien está en mejor posición para resguardarla. Porque desde esta posición el Estado respeta y vela por la soberanía de elección de sus ciudadanos, sin intentar substituirlos (RUIZ SCHNEIDER, 2010). Los individuos, así como la esfera privada, adquieren de este modo el protagonismo de la decisión educativa. La educación pasa a ser un "bien de capitalización individual" que aporta principalmente beneficios personales (LAVAL, 2004, p. 115), y que más tarde permitirá satisfacer deseos y necesidades, en desmedro de una función socializadora. Esta orientación trastoca profundamente los fundamentos de la democracia moderna, es decir el reconocimiento de la educación en tanto que derecho social ligado a la construcción de ciudadanía.

La confluencia en el principio de libertad de enseñanza le permitió al régimen militar no tener que hacer grandes elecciones en torno a un modelo educacional. La divergencia ideológica entre católicos conservadores y neoliberales cede el paso a consideraciones en apariencia meramente factuales, cuyo objetivo se limitaría a garantizar el derecho constitucional de la libertad de enseñanza. Es por esta vía, y a través de este doble discurso, que las cosas se van encauzando poco a poco, dónde la senda de la libertad individual y familiar funciona como horizonte.

Las modernizaciones socio-económicas que ya estaban afectando a toda la estructura institucional de la nación para ajustarse a la economía de mercado, se extienden así a principios de los años 1980 -o sea, casi un lustro después del golpe de Estado- a la esfera educacional. Se pone en marcha una completa restructuración del sistema educacional sobre bases explícitamente neoliberales, inspirada en las proposiciones de Milton Friedman.

\section{La revolución educacional}

La reforma educacional termina con el Sistema Nacional de Educación y se procede a crear un mercado educacional para que las familias puedan ejercer su legítimo derecho a elegir dónde educar a sus hijos. El objetivo es mejorar también la eficiencia del sistema escolar, incrementando el acceso y la calidad de la educación. Se transfiere de este modo el desarrollo del sistema educativo a la interacción de los actores privados en el mercado, privatizando y desestatizando la educación.

En el transcurso de la década de los 80, la gestión administrativa de todos los establecimientos educacionales públicos, de instrucción primaria y secundaria, se deja en manos de sus respectivos municipios, o se ceden a corporaciones privadas sin fines de lucro. Es lo que se conoce como municipalización de la educación pública, y que corona un proceso de descentralización que empezó a principios de la década de 1970. La desconcentración educacional estuvo innumerables veces en el corazón de diversos proyectos políticos, tanto para disminuir la burocracia administrativa, como para que los organismos regionales pudiesen ser parte de las decisiones educativas (ESPINOZA; GONZÁLEZ, 1993). Por la manera en que se desarrolló este proceso bajo el régimen militar, queda en evidencia que del proyecto político inicial que animó la desconcentración educacional no quedó nada, la descentralización no fue más que un instrumento para mejorar la eficiencia de la gestión gubernamental.

Otra novedad de la reforma educativa propiciada por el régimen militar es el cambio en el modo de financiamiento. Las instituciones de educación pública, es decir municipales, comienzan a recibir financiamiento por medio de un subsidio en función de la demanda que satisfacen, ya no en función de sus costos de funcionamiento. Con este sistema, el Estado le transfiere a los establecimientos un bono educativo, o voucher, por cada uno de sus estudiantes, por lo que el subsidio se determina 
en función de la asistencia promedio de los alumnos a cada institución. Es necesario aclarar, que en Chile desde 1951, el Estado subvencionaba por este medio a los colegios privados que participaban de la labor docente estatal. La novedad que introduce la política del régimen militar, es que todo el financiamiento público para la educación escolar se otorga a través de este subsidio, y que por lo tanto no se distingue más entre establecimientos educativos públicos y privados. Desde entonces las instituciones privadas que solicitan la ayuda pública reciben el mismo trato $\mathrm{y}$ subvención del Estado que los establecimientos municipales, lo que da nacimiento a un tercer tipo de instituciones educativas: además de los establecimientos públicos y de las escuelas privadas (que no reciben ayuda pública), aparecen los establecimientos particulares-subvencionados. La ley que introduce estas reformas permite a los establecimientos de educación media cobrar a las familias gastos de escolaridad, hasta un determinado umbral, y seguir percibiendo la subvención (CHILE, 1980). Se abre de este modo la posibilidad que instituciones educativas lucren con la educación, y continúen de percibir fondos públicos.

La lógica subyacente de este sistema, es que el mercado permitiría mejorar la calidad educativa así como el funcionamiento de los centros de educación (AED0; SAPELLI, 2001), puesto que la elección de colegio por las familias funcionaría como un mecanismo de promoción o de sanción a los establecimientos. En definitiva, con la creación del mercado educativo las familias podrán elegir la oferta educativa que más les convenga para sus hijos dentro de una gran variedad de establecimientos, pagando un complemento, si pueden y si lo desean, para acceder a productos educativos diferenciados. Las escuelas pública y privada, con o sin fines de lucro, deberán competir entre ellas para atraer y retener a los alumnos. Son ellos en efecto, y su número, que les permitirán recibir la subvención estatal y permanecer en el sistema. El gobierno por su parte, puede de este modo disminuir los gastos educacionales al limitar su participación a la sola previsión de recursos para la subvención. Conserva sin embargo la potestad para determinar los programas escolares y supervisar el funcionamiento del sistema.

La autorregulación del sistema de educación suponía, para poder funcionar correctamente, que la demanda educativa de las familias esté al tanto del diferencial de la calidad educativa de los colegios. Con este fin, en Chile se desarrollan muy tempranamente instrumentos para medir los resultados de aprendizaje a gran escala de los alumnos, siendo el país pionero en este área en América Latina (COX, 2005). Desde 1988 se empieza a practicar el SIMCE, Sistema de Evaluación de la Calidad Educativa, un sistema de evaluación vigente hasta la fecha.

Notemos que los liceos técnico-profesionales son una excepción de estos procesos, puesto que a ellos se les aplicaron políticas particulares. Es importante recalcarlo porque estos establecimientos educativos fueron víctimas de la primera ola de privatizaciones, antes de la reforma educativa de los años 80 y de la filosofía que terminó poniéndose en práctica; en su caso se procedió a entregarlos a corporaciones educativas creadas por los gremios empresariales. El Estado continuó sin embargo financiando estas formaciones, con subsidios directos a los gremios, bastante más generosas que la subvención entregada al resto del sistema. Se argumentaba que la idea era vincular más estrechamente estas formaciones con el mundo del trabajo, promoviendo una transición exitosa de los estudiantes al mercado laboral. En la práctica esta administración significó un estancamiento en la ampliación de la matrícula escolar para estas formaciones y un importante deterioro de la enseñanza (PIIE, 1984). Por lo demás, se desvalorizó la enseñanza técnica, las familias atraídas por el sistema de instrucción general y las perspectivas profesionales que se abrían para sus hijos, que funcionarían como mecanismo de movilidad 
social, generaron desinterés por este tipo de escuelas. Hubo una suerte de abandono social hacia esta modalidad educativa, que preparaba a los jóvenes para el mundo del trabajo.

En lo que respecta a la educación superior se la dotó de una nueva legislación con "propósitos competitivos" (CHILE, 1981, p. 34), la Ley General de Universidades que modificó también completamente su estructura. La educación superior se diversifica, creando Institutos Profesionales (IP) y Centros de Formación Técnica (CFT). Desde entonces, las universidades y los institutos profesionales impartirían formaciones profesionales, siendo las primeras las únicas autorizadas a entregar adicionalmente grados académicos. Los CFT en cambio estarían orientados a darle continuidad a la enseñanza técnico-profesional, otorgando títulos técnicos de nivel superior.

Además de este cambio estructural, las ocho universidades que existían en 1980 son fragmentadas en múltiples instituciones de educación y se amplía la oferta educacional, estimulando la creación de establecimientos privados de educación superior. Las instituciones públicas de educación superior son forzadas a autofinanciarse, y se instaura un sistema de financiamiento que dispone modalidades de Aporte Fiscal Directo (AFD) a universidades del Consejo de Rectores ${ }^{4}$ e indirecto (AFI) a las instituciones que acogen a los mejores puntajes del examen de selección universitaria existente en esa época, Prueba de Aptitud Académica (MÖNCKEBERG, 2006). Bajo las mismas lógicas que la privatización de la educación escolar primaria y secundaria, se incita la competencia de las universidades, CFT e IP con el fin de incrementar la calidad y la eficiencia del sistema.

En cuanto a los profesores, su labor también se privatiza. El Sindicato Único de Trabajadores de la Educación es desarticulado,

4- Organismo creado en 1954 que reúne a las universidades públicas y a sus derivadas, y a las universidades privadas tradicionales, creadas antes de la reforma de 1981. Sólo este conjunto de universidades beneficia del AFD, un subsidio de libre disponibilidad basado en criterios históricos. y reemplazado por un Colegio de Profesores con dirigentes designados, que intenta cooptar al magisterio (RUIZ; SCHNEIDER, 2010). Además, se pone término a una carrera docente afiliada al estatus de funcionario público $\mathrm{y}$ estos comienzan a depender directamente del código del trabajo. De este modo, la libertad de enseñanza y de pensamiento que eran garantizadas por su status de funcionario, son sacrificadas en aras de la libertad de elección de las familias y de los directores de los centros educativos; como todo otro asalariado se ven supeditados a la voluntad de su empleador, y deben ajustarse y someterse a los vaivenes del mercado. Esto le da mayor flexibilidad al mercado educativo.

Para dar término al conjunto de reformas educativas instauradas a lo largo de los 17 años de dictadura, un día antes que asuma el poder el gobierno elegido democráticamente, se promulga la Ley Orgánica Constitucional de Enseñanza, LOCE. Esto da cuenta cómo la educación, materia en la que el régimen militar no tenía un proyecto explícito, adquiere importancia en el transcurso de los años y deviene un aspecto mayor del proyecto neoliberal, incluso se podría decir que se consolidó como un componente central de la nueva estructura social. El último acto jurídico del régimen autoritario viene entonces a clausurar los cambios educativos implementados en la década de los 80 , y a asegurar su permanencia, haciendo muy difícil su modificación o derogación.

\section{La matriz neoliberal y sus avatares post-dictadura}

El laboratorio de políticas neoliberales que se instituyeron en Chile, dejó instituciones que hoy, casi 25 años después del fin de la dictadura, siguen funcionando. La concertación de partidos de centro-izquierda que encabezó el gobierno por veinte años a partir de 1990 y hasta el 2010, con cuatro mandatos consecutivos, arregló, perfeccionó e hizo perdurar este sistema educativo neoliberal, 
dándole incluso mayor dinamismo. El mercado por su parte fue demostrando que no era eficiente en la mejoría de los resultados educacionales, siendo, sobre todo, una fuente de incremento de la segregación escolar. No es hasta las movilizaciones estudiantiles del 2006 y luego con mayor ímpetu aquellas del 2011, en que los estudiantes junto a otros actores de la sociedad chilena, que se van sumando a este movimiento, ponen en cuestión las bases del modelo educativo dando inicio a un periodo de revisión, de discusión y de propuestas de otro tipo de institucionalidad educativa. En 2014, por primera vez, bajo el segundo gobierno de Michelle Bachelet (2014-2018), se discute una reforma al modelo educacional que apunta directamente a algunas de sus bases.

Con la vuelta a la democracia, han sido numerosas las políticas y los programas que se han aplicado en los distintos niveles del sistema educativo, bajo el doble lema de mejorar la calidad y la equidad de la enseñanza. La educación deviene, con el primer gobierno de la concertación (1990-1994), la piedra angular del proceso de democratización social, que se consideró como una tarea nacional y prioritaria (UNDURRUAGA, 1999, p. 43). Los gobiernos que se sucedieron incrementaron drásticamente el gasto público que prácticamente se sextuplica en 20 años, pasando a representar de un 2,3\% del PIB en 1990 a un 4,2\% en 2010, e implementaron políticas para el desarrollo del sector educativo. Se reformó el currículo, se establecieron programas de apoyo escolar, se estableció un estatuto nacional que protegía al gremio docente, se crearon políticas para fomentar la participación de diferentes actores educativos, se alargó la jornada escolar, así como los años de educación obligatoria, entre otros (COX, 2012). Sin embargo, este conjunto de innegables inflexiones, se hicieron siempre dentro del marco institucional heredado por la dictadura militar, consolidando por ende el mercado educativo bajo la lógica de lo que Garretón (2012) denominó neoliberalismo corregido y progresismo limitado ${ }^{5}$.

5- Título de su libro en el que analiza los diferentes gobiernos de la concertación, publicado en 2010.
En 1993, tres años después del retorno de la democracia, se aprueba la Ley de financiamiento compartido ${ }^{6}$. Esta reforma buscaba aumentar los recursos destinados a educación, incentivando la movilización del sector privado. Se cambió la legislación en relación a las donaciones de empresas privadas a fines educacionales, con disminuciones del impuesto a la utilidad, y se flexibilizaron los requisitos para abrir colegios particulares con subvención estatal.

Apesar de la modestia aparente de las medidas tomadas, se trató de una inflexión significativa. Las modificaciones en relación a la subvención que permitian un co-pago superior al monto de la subvención, en efecto, cambiaron radicalmente la cartografía del sistema escolar. La llamada Ley de financiamiento compartido provocó un incremento exponencial de los establecimientos particulares subvencionados, en detrimento del sector municipal, y fortaleció la mecánica de la competencia entre escuelas. Se observa de hecho que entre 1990 y el 2010, la matricula municipal (o sea en los establecimientos públicos) disminuye casi un 30\%, pasando de un 59\% a un 42\% del total de la matrícula. En cambio, la matrícula del sector particular subvencionado aumenta de un 50\%, pasando de representar un 33\% del mercado en 1990, a un 50\% el 2010. La tasa de escolarización en la educación privada (sin subsidio público), se movió marginalmente en el periodo, y en el 2010 un 7,7\% de alumnos asistía a colegios particulares pagados (COX, 2012).

El éxito del co-pago instaló una barrera económica para diferenciar al alumnado según la capacidad socioeconómica de las familias, incrementando la desigualdad intrínseca del funcionamiento del mercado. Diversos estudios (BELLEÏ, 2013; HSIEH; URQUIOLA, 2006) muestran cómo ha impactado esta estructura educacional en la estratificación escolar. Esto nos permite afirmar, que la educación particular subvencionada estableció, en efecto, dinámicas

6- No se trata de una ley, sino de una glosa en la ley de presupuesto. 
muy eficaces de segregación, creando verdaderos guetos escolares, y serios problemas de integración e inclusión en el sistema de educación.

En cuanto a la educación superior, sólo se realizaron ajustes menores y la arquitectura del modelo también se mantuvo. Entre tanto la tasa de escolarización aumentó en más del doble, llegando a representar en 2011 un 44,51\% de cobertura en jóvenes entre 18 y 24 años (Base de datos SITEAL ${ }^{7}$ ). Esta masificación de la educación superior esconde empero una realidad más difícil; altos niveles de deserción, títulos desprovistos de valor en el mercado laboral y, sobre todo, enormes costos pecuniarios para los estudiantes, que muchas veces hipotecan su vida para entrar a estudiar. Las familias son la principal fuente de ingreso del sistema de educación superior, los estudiantes llegan a pagar US $\$ 4.000$ anuales en promedio para poder cursar estudios superiores. Los préstamos otorgados con aval del Estado, de los que en 2012 se habían beneficiado más de 455.000 estudiantes, dejaban en promedio US $\$ 4.900$ de deuda por estudiante (HERNÁNDEZ, 2012).

Através de resquicios legales, muchas universidades, CFT e IT han podido lucrar con la educación, algunas de ellas generando importantes dividendos económicos. Una mercantilización tal de la enseñanza superior, que, muchas veces, ha significado un negocio en el que se transan las carteras de alumnos ${ }^{8}$ (MÖNCKEBERG, 2006), y que ha sido develado por numerosos escándalos en estos últimos años.

Con el transcurso de los años, el mercado educativo se consolida en todos los niveles. La ampliación y diversificación de la oferta educativa permite, en teoría, que las familias, así como los estudiantes, tengan una mayor libertad de elección educativa. En la práctica, esta elección está supeditada a la capacidad económica del núcleo familiar, o a su capacidad

7- SITEAL - Sistema de Información de Tendencias Educativas en América Latina (www.siteal.org).

8- Este término hace referencia al conjunto de clientes de una empresa que incrementa su valor comercial, en ese sentido algunas entidades de educación superior han comercializado a sus estudiantes en operaciones de compra-venta de instituciones o fusiones por algún holding educacional. de endeudamiento. Oferentes y demandantes estrechan relaciones comerciales con el fin de transar educación, que se concibe como un bien de consumo, una mercancía.

En el sistema educativo así construido, la competencia se generaliza, todos compiten con todos, dentro de desigualdades y de diferenciales de recursos muy importantes. Los alumnos y sus familias compiten por acceder a mejores estudios, mejores escuelas. Los niños se preparan desde chicos para tener buenos rendimientos en las pruebas de selección de los colegios a los que los padres pueden o quieren acceder. Más tarde compiten en la prueba de selección universitaria, para poder acceder a las universidades más reputadas. Por otro lado, los establecimientos compiten entre ellos a través de sus resultados, del prestigio, de los servicios que ofrece para atraer alumnos, para percibir los recursos de la subvención.

Talvez es aquí, en el ámbito educativo, donde el modelo neoliberal logró sus máximos objetivos. Los distintos actores de la esfera educativa interactúan entre sí a través de relaciones de transacción y competencia, tratando sistemáticamente de maximizar sus resultados en esta interacción y mejorar sus rendimientos, en una suerte de culto a la eficiencia (DARDOT; LAVAL, 2010). Esta adscripción a la filosofía de la competencia ha terminado incluso sentando nuevas bases para comprender la justicia social, que se basa en la valorización del esfuerzo y del trabajo personal, y, por sobre todo, en la recompensa del mérito (ARAUJO; MARTUCCELLI, 2012). La individualización en demasía de los actos, decisiones, éxitos y fracasos de cada cual, expanden el mérito como valor supremo, tanto de reconocimiento como de juicio, desconociendo elementos contextuales o estructurales. El reconocimiento del mérito es en el fondo lo que concentra los anhelos de igualdad social.

En este marco, las técnicas de evaluación se generalizan. Se evalúa regularmente el rendimiento de los alumnos en función de objetivos que establece el sistema escolar, ya sea para medir el nivel de aprendizaje de 
los estudiantes, la eficacia pedagógica de los profesores, la calidad de los colegios, entre otros; incorporando además criterios de evaluación utilizados en pruebas internacionales, esto para poder esgrimir diagnósticos, adoptar programas y políticas gubernamentales. Todo gira en torno a resultados y evaluaciones, verdaderos fetiches del modelo, en donde y al fin de cuentas el resultado se transforma en el fin en sí mismo. Para ello se importan técnicas del management, el tríptico "objetivo-evaluaciónsanción” (DARDOT; LAVAL, 2010, p. 383) al sistema educacional haciendo que cada actor sea responsable de sus rendimientos y deba funcionar como una empresa. Todo es en pro de adquirir las competencias que exige la evaluación, en aras de producir resultados, una lógica a la cual deben plegarse todos los actores en juego.

La cultura de la evaluación que se impone, orienta renovaciones metodológicas y jerarquías de aprendizaje hacia la adquisición de competencias más acordes al mismo modelo. Los indicadores con los que se evalúa, que se supone son indicadores técnicos, son en el fondo decisiones políticas (MARTUCCELLI, 2010). En este caso, los indicadores seleccionados son también competencias de cómo desenvolverse en una estructura neoliberal. Es la lógica económica misma, que determina el sentido de la eficiencia. La educación al concebirse y evaluarse desde criterios en apariencia estrictamente técnicos, transforma de manera reduccionista las metas educativas, al considerar el conocimiento como una adquisición de competencias, el saber se despoja de los valores a los cuales fue tradicionalmente asociado, perdiendo a su vez el estímulo a la reflexión.

Por lo demás, las evaluaciones sistemáticas que se han aplicado en los colegios no han aumentado la transparencia. Si bien esta se concibió como una herramienta para entregar información fehaciente a los consumidores educativos, o sea a las familias para poder hacer sus elecciones, en realidad los resultados no se hicieron públicos sino en el año 1995, e incluso desde entonces son de difícil acceso, sobre todo para las familias de menores recursos. En el fondo, varias investigaciones sugieren que son otros los factores que inciden en la elección de la institución educativa a la que las familias envían a sus hijos, entre los que destaca un criterio de distinción social (ELACQUA; SCHNEIDER; BUCKLEY, 2006; HERNÁNDEZ; RACZYNSKI, 2010). Esto sobre todo en los estratos medios, en que las familias buscan diferenciarse de los estratos más populares, eligiendo establecimientos escolares en los que el perfil socioeconómico del alumnado sea acorde a la percepción que estas tienen de ellas mismas, y a las aspiraciones del medio en el que quieren que sus niños se desarrollen.

Por último, pero no por eso menos importante, cabe señalar que esta política de la evaluación contribuyó a mercantilizar la educación y fomentar lógicas clientelistas, así como demandas de calidad. Todo gira en torno a indicadores de productividad, a las cifras contables.

\section{Conclusión}

El sistema educacional chileno se vio profundamente trastocado por transformaciones neoliberales que revolucionaron el modelo educacional. De este proceso, prematuro para las transformaciones de la región, podemos concluir que:

1. En su origen, la dictadura militar no tenía un proyecto explícito para la educación. No obstante, progresivamente esta se convirtió en uno de los sectores-pilares del modelo neoliberal;

2. El modelo que se impuso en Chile, en los hechos, de clara impronta neoliberal, fue el resultado, más o menos coyuntural, de la convergencia entre la ideología católicaconservadora y la ideología neoliberal en torno a la libertad de enseñanza;

3. El sistema educativo de matriz neoliberal se impuso en Chile a partir de los años 80. Desde entonces, a pesar de inflexiones significativas, su filosofía siguió vigente;

4. Pese a que la matriz neoliberal se implementó de manera diferente para 
los distintos niveles educativos (primaria, secundaria), ésta se caracterizó empero por darle al sistema educativo una coherencia ideológica de conjunto: la libertad de elección se volvió su verdadero núcleo;

5. Las grandes promesas del modelo educacional neoliberal están lejos de concretizarse, sobre todo aquellas que prometían mayor equidad en la educación y mejor calidad de los resultados de aprendizaje gracias a la competencia entre establecimientos. Son estas las frustraciones que gatillaron las protestas estudiantiles del 2006 y del 2011, y que fueron abordadas transversalmente en las últimas elecciones presidenciales ${ }^{9}$ por todos los actores políticos.

\footnotetext{
9- El año 2013, elecciones en las que fue electa para un segundo período
} Michelle Bachelet quien asumió el cargo en marzo del 2014.
6. Sin embargo, a pesar del fracaso del modelo en relación a sus propias promesas, el sistema educacional neoliberal recibió el respaldo de muchas familias. Así lo demuestra el incremento sustancial de la matrícula en el sector particular-subvencionado, y la paulatina desvalorización de la educación pública.

7. Por ende, en Chile, el mayor logro del modelo neoliberal fue atentar contra la idea de educación pública, y poner en jaque la educación en tanto bien social. Se entroniza en cambio la filosofía de la competencia generalizada entre los distintos actores, haciendo de la educación un bien de consumo, una mercancía.

8. La historia analítica desarrollada en el artículo, permite comprender por qué es alrededor de la educación que se concentra hoy en Chile el malestar del modelo de mercado y la pugna ideológica que ella conlleva.

\section{Referencias}

AEDO, Cristián; SAPELLI, Claudio. El sistema de vouchers en educación: una revisión de la teoría y evidencia empírica para Chile. Estudios Públicos, n. 82, p. 35-82, otoño 2001.

ARAUJO, Katia; MARTUCCELLI, Danilo. Desafíos comunes: retrato de la sociedad chilena y sus individuos. v. 2. Santiago: LOM, 2012.

BELLEÏ, Cristián. El estudio de la segregación socioeconómica y académica de la educación chilena. Estudios Pedagógicos, Valdivia, v. 39, n. 1, p. 325-345, 2013

BRUNNER, José Joaquín. Informe sobre la educación superior en Chile. Santiago: Flacso, 1986.

CHILE. Declaración de principios de la Junta de Gobierno. Santiago: Junta de Gobierno, 1974.

CHILE. 3.476 Decreto Ley 5, 1980. Fija normas a los establecimientos de enseñanza particular subvencionados por el Estado. Ley Chile, Santiago, 1980. Disponible en: < http://www.leychile.cl/N?i=7138\&f=1980-11-01\&p=>. Acceso en: 23 abr. 2014.

CHILE. Secretaría General del Consejo de Rectores. Nueva Iegislación universitaria chilena. Santiago: Secretaría General del Consejo de Rectores, 1981.

COX, Cristián. Las políticas educacionales de Chile en las últimas dos décadas del siglo XX. In: COX, Cristián (Ed.). Políticas educacionales en el cambio de siglo: la reforma del sistema escolar de Chile. Santiago: Universitaria, 2005. p. 19-113.

COX, Cristián. Política y políticas educacionales en Chile 1990-2010. Revista Uruguaya de Ciencia Política, Montevideo, v. 21, n. 1, p. 13-42, 2012.

COX, Cristián; JARA, Cecilia. Datos básicos para la discución de políticas en educación (1970-1988). Santiago: CIDE, 1989.

DARDOT, Pierre; LAVAL, Christian. La nouvelle raison du monde: essai sur la société néolibérale. Paris: La Découverte, 2010.

ELACQUA, Gregory; SCHNEIDER, Mark; BUCKLEY, Jack. School choice in Chile: is it class or the classroom? Journal of Policy Analysis and Management, Washington, DC, v. 25, n. 3, p. 577-601, 2006. 
ESPINOZA, Oscar; GONZÁLEZ, Luis Eduardo. La experiencia del proceso de desconcentración y descentralización educacional en Chile 1974-1989. Santiago: CEME, 1993. Programa Interdisciplinario de Investigaciones en Educación. Disponible en: <http://www.archivochile.com/edu/doc_gen/edudocgen00001.pdf>Acceso n: 12 sep. 2013.

GARRETÓN, Manuel Antonio. Neoliberalismo corregido y progresismo limitado: los gobiernos de la concertación en Chile, 1990 - 2010. Santiago: Arcis-Clacso-Proposal, 2012.

HARVEY, David. A brief history of neoliberalism. Oxford: Oxford University Press, 2007.

HERNÁNDEZ, Macarena; RACZYNSKI, Dagmar. ¿Cómo eligen escuelas las familias chilenas de estratos medios y bajos? Información, representaciones sociales y segregación. In: Congreso Interdisciplinario de Investigación en Educación, 1., 2010, Santiago. Primer... Santiago: Universidad de Chile. Pontificia Universidad Católica de Chile, 2010. p. 13. Disponible en: <http:// www.ciie2010.cl/?page=view_programa_completo>. Acceso en: 25 sep. 2014.

HERNÁNDEZ, Vladimir. ¿Por qué es tan cara la universidad en Chile? BBC Mundo, 16 mayo 2012. Disponible en: <http://www. bbc.co.uk/mundo/noticias/2012/05/120515_chile_educacion_costo_protestas_vh.shtml>. Acceso en: 04 sep. 2014.

HSIEH, Chang-Tai; URQUIOLA, Miguel. The effects of generalized school choice on achievement and stratification: evidence from Chile's voucher program. Journal of Public Economics, v. 90, p. 1477-1503, 2006.

LAVAL, Christian. L'école n'est pas une entreprise: le néo-libéralisme à l'assaut de l'enseignement public. Paris: La Découverte, 2004.

MARTUCCELLI, Danilo. Critique de la philosophie de l'évaluation. Cahiers Internationaux de Sociologie, Paris, v. 128-129, n. 1, p. 27-52, 2010.

MÖNCKEBERG, María Olivia. La privatización de las universidades: una historia de dinero, poder e influencias. Santiago: La Copa Rota, 2006.

PIIE. Programa Interdisciplinario de Investigaciones en Educación. Las transformaciones de la educación bajo el régimen militar. v. 1. Santiago: PIIE, 1984.

RUIZ SCHNEIDER, Carlos. De la república al mercado: ideas educacionales y política en Chile. Santiago: LOM, 2010.

UNDURRAGA, Consuelo. El proceso de reformas puertas adentro: la experiencia del ministro. In: ESPÍNOLA, Viola; MOURA CASTRO, Claudio (Eds.). Economía política de la reforma educacional en Chile: la reforma vista por sus protagonistas. Washington, DC: BID, 1999. p. 41-57.

VALDIVIA ORTIZ DE ZÁRATE, Verónica. Estatismo y neoliberalismo: un contrapunto militar. Chile 1973-1979. Historia, Santiago, n. 34, 2001. Disponible en: <http://www.scielo.cl/scielo.php?script=sci_arttext\&pid=S0717-71942001003400006\&lng=es\&nrm= iso\&tlng=es>. Acceso en: 2014.

Recebido en: 14.10.2014

Aprobado en: 09.12.2014

Natalia Slachevsky Aguilera es doctoranda en sociología de la Universidad París Descartes, USPC, CERLIS-CNRS. Licenciada en economía de la Facultad de Economía y Negocios de la Universidad de Chile, magíster en sociología en la EHESS (École des Hautes Études en Sciences Sociales). 